\title{
A Spatio-Temporal Analysis of Dengue Fever in West Bengal with Special Reference to Kolkata Municipal Corporation Area
}

\author{
Anandita Dawn \\ Junior Research Fellow, Department of Geography, University of Calcutta, Kolkata, West Bengal, India
}

\begin{abstract}
Dengue Fever is the most rapidly spreading vector-borne viral disease in the world. The disease which spreads through the bite of the infected female Aedes aegypti species of mosquito have now emerged as a serious threat to human health in India as well. Out of the 18 endemic states of India, the state of West Bengal has been identified as one of the severely affected states. This paper attempts to trace the socio-economic and environmental causes responsible for the outbreak of the disease in the city of Kolkata considered as the administrative and health hub of the state. The city experiences quite a massive outbreak during monsoon and post-monsoon season especially in the months of August, September and October though stray dengue cases are reported perennially with a number of deaths over the past few years. A striking contrast can be seen among the slum dwellers and non-slum communities regarding the scenario of outbreak of the disease. The disease assumes quite a horrifying picture in the slum areas of the city with maximum deaths reported from these areas. The Government run health institutions become loaded with dengue patients every year. The mortality rate increases due to wrong clinical findings and careless treatment by the pathologists and physicians. In recent years with the initiatives of the Government the death toll was controlled to some extent, though the attempt was appreciable but it fall far short than the actual requirement.

Key words: dengue fever, aedes mosquito, vector-borne disease, dengue virus, serotypes
\end{abstract}

\section{Introduction}

Dengue Fever is one of the most common mosquito-borne diseases caused by dengue virus belonging to the family of Flaviviridae having four serotypes- DENV-1, DENV-2, DENV-3 and DENV-4. The disease is spread through the bite of the infected female Aedes aegypti species of mosquito. This species of mosquito is usually found between $35^{\circ} \mathrm{N}-35^{\circ} \mathrm{S}$ latitude below an elevation of 1,000 metres. In the last 50 years, incidence has increased 30-fold with increasing geographic expansion to new countries beyond national borders (WHO, 2009). The first clinically recognized dengue epidemic was recorded almost simultaneously in Asia, Africa and North America in the 1780s. The first outbreak was documented in India in 1780 in Chennai (erstwhile Madras). The first major widespread epidemic of the disease occurred in India in 1996 in the areas around Delhi and Lucknow. Dengue fever has often become epidemic in various parts of India since 1987. Out of the 18 endemic states West Bengal has been identified as one of the states severely affected by the disease every year.

\section{Objectives of the Study}

The study has been initiated to fulfil the following objectives:

$\oplus$ To find out the environmental conditions conducive for the outbreak of dengue fever

4 To trace the spatial variations of the disease in different parts of Kolkata

$\oplus$ To identify the socio-economic reasons behind the prevalence of the disease in slum households of the city

4 To know about the variations of outbreak of the disease among people based on their housing condition

4 To assess the role of Government and Non-Government Organizations in controlling the spread of the disease

4 To study the level of awareness among common people regarding the danger of mosquito bite leading to dengue fever

\section{Area under Study}

The Kolkata Municipal Corporation has a total area of $187.33 \mathrm{sq} . \mathrm{km}$ with a geographical extension of $22^{\circ} 27^{\prime} \mathrm{N}$ to $22^{\circ} 39^{\prime} \mathrm{N}$ latitude and $88^{\circ} 14^{\prime} \mathrm{E}$ to $88^{\circ} 26^{\prime} \mathrm{E}$ longitude. The territorial jurisdiction of Kolkata Municipal Corporation has been divided into 15 Boroughs consisting of 141 municipal wards. Spatially the city can be divided into North, East, Central and South Kolkata. The district of Haora lies to the North-West, North 24 Parganas on the Northern and North-Eastern side and South 24 Parganas on the South-Eastern and SouthWestern side. The River Hugli flows through Western part of the city. 


\section{Data Base and Methodology}

The work is a combination of both primary and secondary data. Information was generated on environmental conditions of the slum households as well as the socio-economic causes responsible behind the prevalence of the disease especially in the slum areas of the city. Most of the secondary data were collected from Health Department, Government of West Bengal and Kolkata Municipal Corporation (KMC). Besides, primary data were also collected. A number of articles from various journals and reports of World Health Organization (WHO) have also been consulted for the purpose.

Apart from computation of the available secondary data and their cartographic representation, questionnaires were framed for the target groups of doctors, hospital staff and patients for generation of primary data. Purposive method of sampling was followed with a sample size of 40 doctors, 75 hospital staffs and 200 patients from both slum and non-slum households representing 15 Boroughs in the city. Field investigation for ground truth verification was conducted inside the Government run hospitals and blood testing clinics along with the slum households too.

\section{Scenario of Dengue Fever in India}

Dengue Fever (DF) is one of the rapidly growing public problems in tropical and subtropical countries of the world. The disease has affected population across the world especially countries of South-east Asia including Bangladesh, Maldives, Sri Lanka, Indonesia, Thailand and Myanmar [Table.1]. It has emerged as one of the grave health issues in India as well. The clinical presentations of the febrile phase include a milder nonlocalizing fever syndrome associated with joint and muscle pain, abnormally low platelet count, red spots or rashes on skin, vomiting, nausea and diarrhoea [Box.1]. Although dengue infection has become epidemic in the country since $19^{\text {th }}$ century, the Dengue Haemorrhagic Fever (DHF) has become endemic in various parts of India since 1987 (Halasa, et.al. 2011). The first major outbreak of DHF and Dengue Shock Syndrome (DSS) in epidemic form was reported during 1996 involving areas around Delhi, Lucknow, Uttar Pradesh, and spreading to other regions as well. Recurring outbreaks of DF/ DHF have been reported from various States / Union Territories (UTs) namely Andhra Pradesh, Delhi, Goa, Haryana, Gujarat, Karnataka, Kerala, Maharashtra, Rajasthan, Pondicherry, Punjab, Tamil Nadu, West Bengal and Chandigarh (Ministry of Health and Family Welfare, 2008). The predominant serotype observed in 1996 was DEN-2, whereas all dengue serotypes were detected in 2003 outbreak in north India. However, the outbreak in 2005 in Delhi was mainly due to DEN-3 serotype (Sharma, et.al. 2010).

Table.1: Dengue Fever in South-East Asia Region

\begin{tabular}{|c|l|c|}
\hline Category & \multicolumn{1}{|c|}{ Characteristics } & Countries \\
\hline I & $\begin{array}{l}\text { Epidemics caused by all 4-serotypes, high morbidity among children, } \\
\text { epidemics every 3-5 years, spreading to rural areas }\end{array}$ & $\begin{array}{c}\text { Indonesia, Thailand } \\
\text { Myanmar }\end{array}$ \\
\hline II & $\begin{array}{l}\text { DHF is an emergent disease, epidemics more frequent, multiple serotypes, } \\
\text { spreading within countries }\end{array}$ & $\begin{array}{c}\text { Bangladesh, India, } \\
\text { Maldives, Sri Lanka }\end{array}$ \\
\hline III & No reported cases, endemicity is uncertain & Bhutan, Nepal \\
\hline IV & Without dengue epidemic & DPR Korea \\
\hline
\end{tabular}

(After Tyagi, 2012)

Box.1: Clinical Symptoms Associated with Dengue Fever

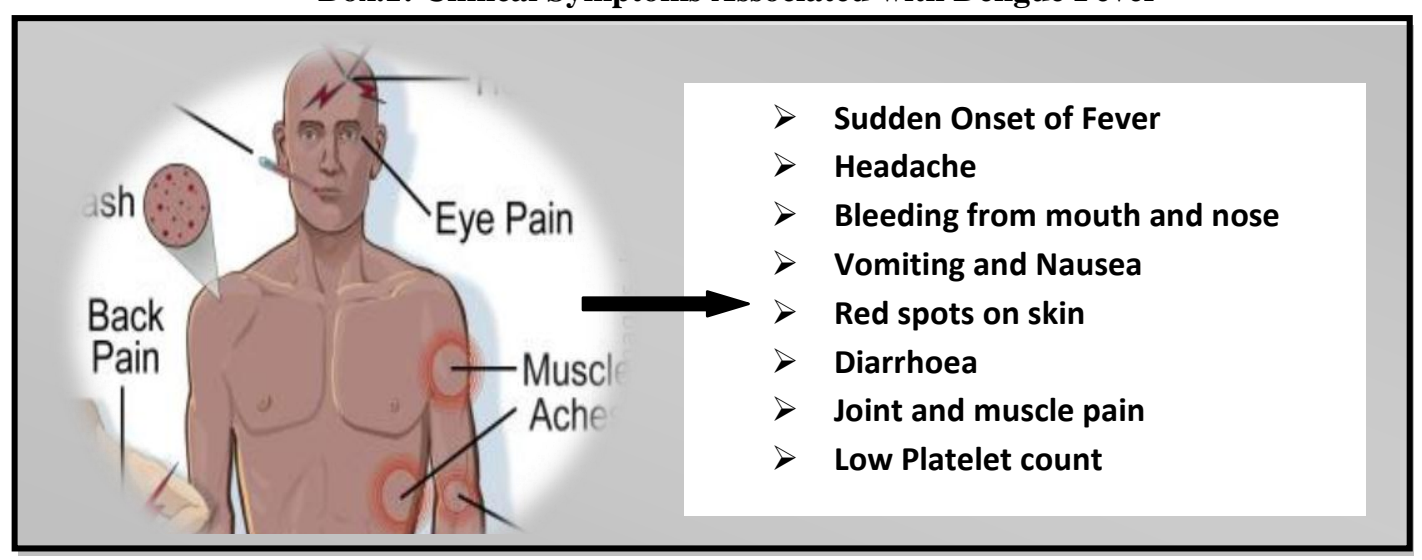

In the year 1996 one of the most severe outbreaks of the disease occurred in Delhi where 10,252 cases were reported with a high death toll of 423. In 2006, a massive outbreak occurred in 21 states and UTs with a total of 12,317 cases and 184 deaths. The Case Fatality Rate (CFR) of the disease was 1.3, 0.6, 0.6, and 0.4 per cent in the year 2007, 2008, 2009 and 2010 respectively [Table.2]. The CFR shows a maximum variation for 
major states like Odisha, Madhya Pradesh, Assam, Kerala and Haryana where the curve shows an upward trend during the year 2006 and 2010 [Fig.1]. In case of Odisha there has been a tremendous increase in CFR during 2010 while Kerala exhibits a slight increase during the same year. No CFR could be observed during 2006 and 2010 in major states like Chhattisgarh, Himachal Pradesh, Bihar and Jharkhand. The lowest CFR was observed in case of Gujarat while Jammu and Kashmir recorded no CFR during 2010 although the state recorded quite a high number of deaths during 2006.

Table.2: Year-wise Incidences of Dengue Fever in India, 2007-2011

\begin{tabular}{|l|r|r|r|r|r|}
\hline \multicolumn{1}{|c|}{ Year } & \multicolumn{1}{|c|}{$\mathbf{2 0 0 7}$} & $\mathbf{2 0 0 8}$ & $\mathbf{2 0 0 9}$ & \multicolumn{1}{|c|}{$\mathbf{2 0 1 0}$} & $\mathbf{2 0 1 1}^{*}$ \\
\hline Number of Cases & 5,534 & 12,561 & 15,535 & 28,292 & 1,198 \\
\hline Number of Deaths & 69 & 80 & 96 & 110 & 07 \\
\hline Case Fatality Rate (in \%) & 1.3 & 0.6 & 0.6 & 0.4 & 0.6 \\
\hline *upto May
\end{tabular}

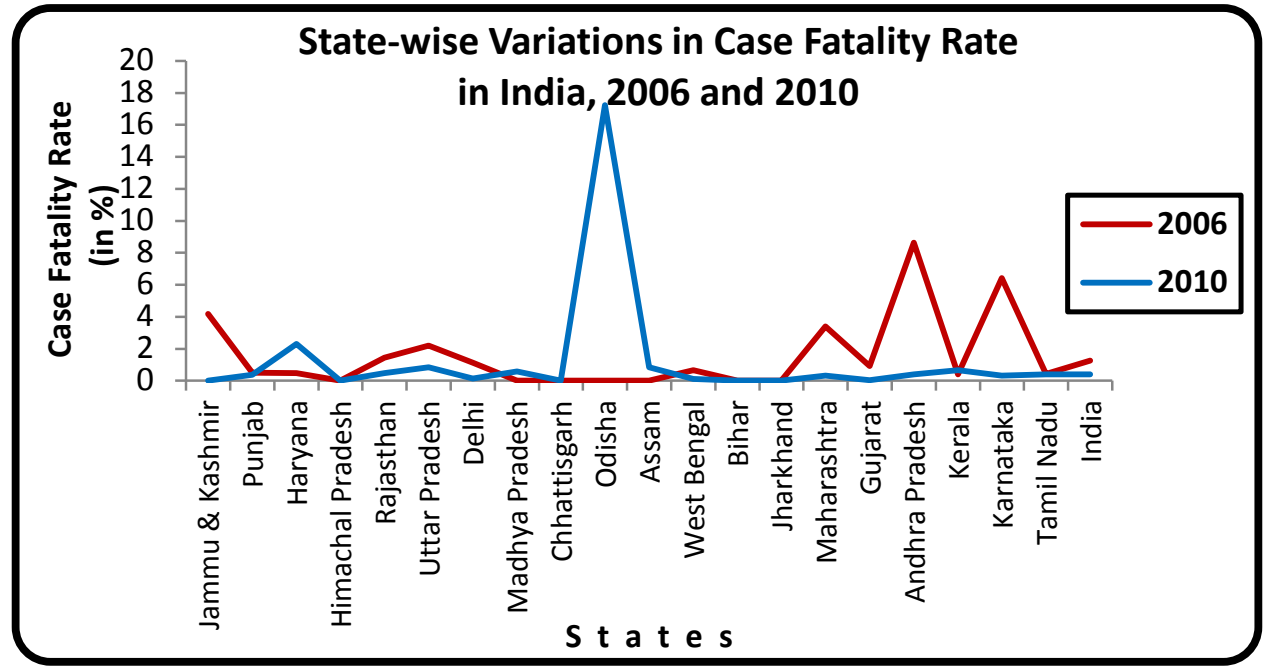

Fig.1 Data Source: Ministry of Health and Family Welfare, Govt. of India

The incidence of DF/ DHF is particularly seen during monsoon months of August to early October. During this period the country receives maximum rainfall from South-west monsoon [Fig.2]. This is a vital season for Indian agriculture since the amount of rainfall controls the yield of the crops. In drier parts of the country the monsoon rain is retained and stored by various water harvesting techniques. In the post monsoon season especially during the months of late October and November the incidences of dengue remain quite high especially in the eastern states of Odisha and West Bengal. The incidences of dengue in West Bengal especially in the city of Kolkata are related with the environmental and socio-economic conditions of the city dwellers. A shift in the month-wise trend of DF/DHF could be observed during the year 2005 and 2007. During the year 2005 maximum incidences of the disease took place during monsoon season while during 2007 maximum incidences could be seen during post-monsoon.

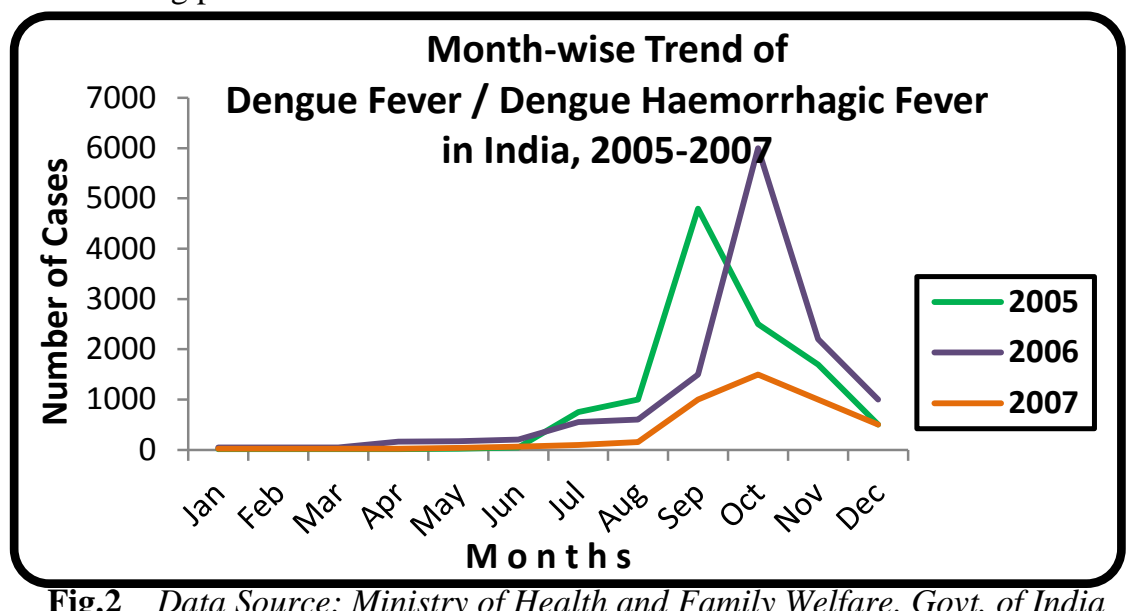


During the year 2011 the CFR for India was 0.90 per cent, Chhattisgarh recorded the highest CFR of 3.51 per cent followed by Uttar Pradesh (3.22\%) and Maharashtra (2.20\%) in the same year. The major states of Assam, Bihar, Himachal Pradesh, Jammu and Kashmir, Madhya Pradesh and West Bengal recorded no CFR in 2011. The major states which recorded CFR above national rate are Chhattisgarh, Haryana, Karnataka, Maharashtra, Odisha and Uttar Pradesh while Andhra Pradesh, Gujarat, Kerala, Punjab, Rajasthan and Tamil Nadu are the states with CFR below than national rate of 0.90 per cent [Table.3].

Table.3: State-wise Case Fatality Rate in India, 2011

\begin{tabular}{|l|r|r|}
\hline \multicolumn{1}{|c|}{ Major States } & $\begin{array}{c}\text { Case Fatality Rate } \\
\text { (in \%) }\end{array}$ & Position \\
\hline Chhattisgarh & 3.51 \\
\hline Uttar Pradesh & 3.22 \\
\hline Maharashtra & 2.20 \\
\hline Odisha & 1.82 \\
\hline Karnataka & 1.23 \\
\hline Haryana & 1.12 \\
\hline INDIA & $\mathbf{0 . 9 0}$ \\
\hline Punjab & 0.84 \\
\hline Kerala & 0.77 \\
\hline Gujarat & 0.53 \\
\hline Andhra Pradesh & 0.50 \\
\hline Rajasthan & 0.37 \\
\hline Tamil Nadu & 0.36 \\
\hline Assam & 0.00 \\
\hline Bihar & 0.00 \\
\hline Himachal Pradesh & 0.00 \\
\hline Jammu and Kashmir & 0.00 \\
\hline Jharkhand & 0.00 \\
\hline Madhya Pradesh & 0.00 \\
\hline West Bengal & $\mathbf{0 . 0 0}$ \\
\hline Source Computed from the data provided by Ministry of Health and Family Welfare
\end{tabular}

\section{Outbreak of Dengue Fever in West Bengal}

Dengue is a self limiting acute mosquito transmitted disease characterized by fever, headache, muscle, joint pains, rash, nausea and vomiting (Ministry of Health and Family Welfare, Government of India, 2008). In the last decade, dengue has assumed Pan-India proportions. Outbreaks and deaths have been reported from northern states of Haryana, Punjab and Uttar Pradesh; southern states of Andhra Pradesh, Tamil Nadu and Karnataka; western states of Gujarat and Rajasthan; and eastern state of West Bengal (Sharma, et.al. 2010). Dengue was essentially an urban disease in the state of West Bengal though it has changed its character in course of time. In 1994 dengue fever in epidemic form was recorded in the rural areas of the state. The month of July in the year 2012 was observed as the 'anti dengue month'. Despite the entire efforts outbreak struck during August and the number of cases reported were more than expected from Kolkata as well as adjoining districts. During 2005-07 the percentage of confirmed cases to total outbreak was highest in Kolkata (63.76\%) under Presidency administrative division and least in Jalpaiguri (0.02\%) under Jalpaiguri administrative division [Fig.3]. It is noteworthy to mention that all the districts under Jalpaiguri administrative division recorded 0.022.46 per cent of confirmed cases while the districts under Presidency administrative division excluding the district of Murshidabad has recorded 1.35-63.76 per cent of confirmed cases. The year-wise number of dengue fever cases has been showing a declining trend since 2011 though peak incidences were observed during 2010 [Fig.4]. 


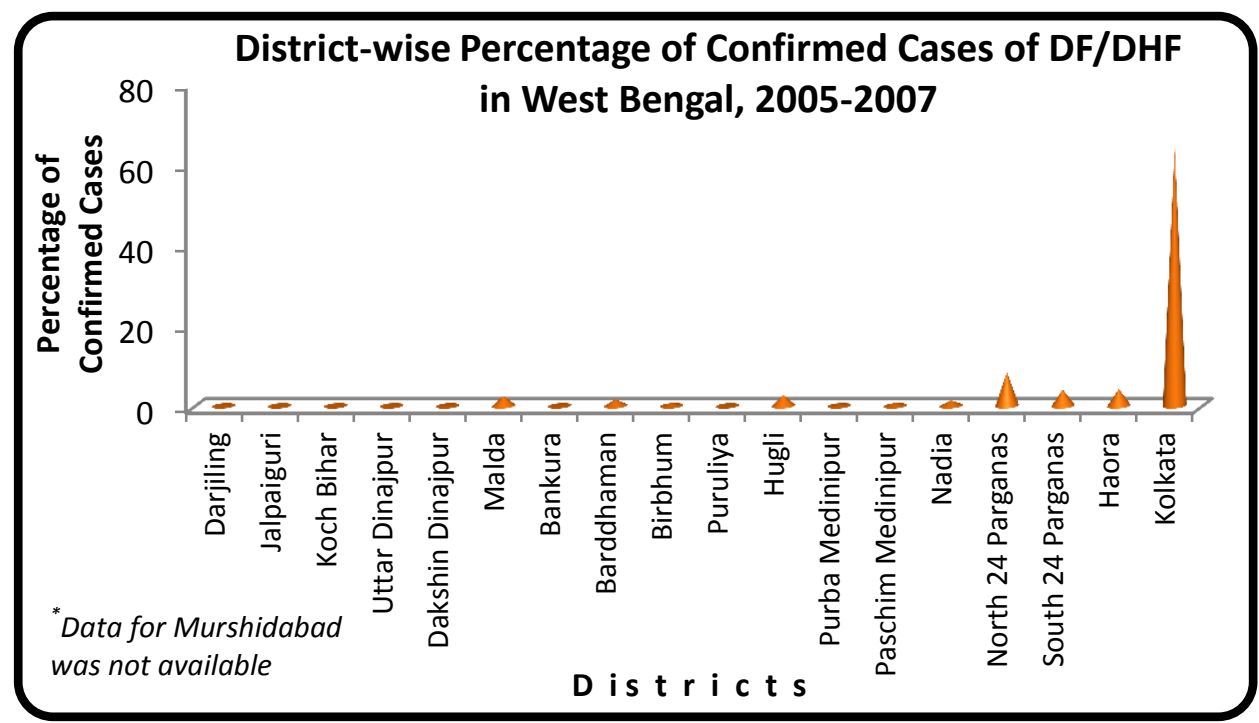

Fig.3

Data Source: Govt. of West Bengal

The total cases diagnosed as dengue during August-November, 2005 by the Government of West Bengal were 6,293. The total deaths occurred during this period were 34 thus the CFR was 0.54 per cent of which 27 were seropositive cases. During this outbreak, prevailing dengue serotype was the Den-3 (Hati, 2006).

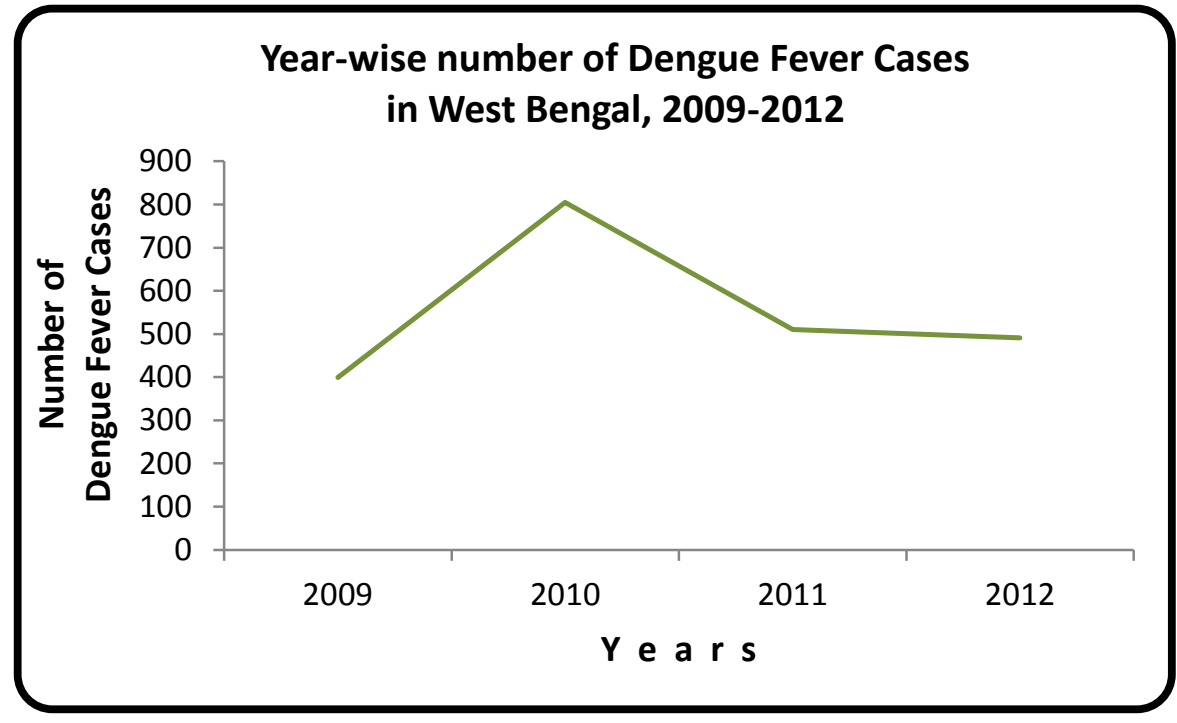

Fig.4

Data Source: Govt. of West Bengal

Among the districts of Jalpaiguri division Kochbihar, Darjiling, Jalpaiguri and Uttar Dinajpur recorded no incidences of dengue fever cases during the year 2009 while among the districts of Barddhaman division Barddhaman recorded the highest number of cases of the disease during the same year. In Kolkata an abnormal occurrence of dengue fever cases were observed in 2009 though the official figures counted no death in the city with highest health infrastructure in the state. It was estimated that 68.42 per cent of the districts recorded less than 15 cases of dengue fever, 15.79 per cent of the districts recorded 15-30 cases, 10.53 per cent of the districts recorded 30-45 cases and only 5.26 per cent of the districts recorded more than 45 cases of the disease under study during 2009 [Fig.5]. 


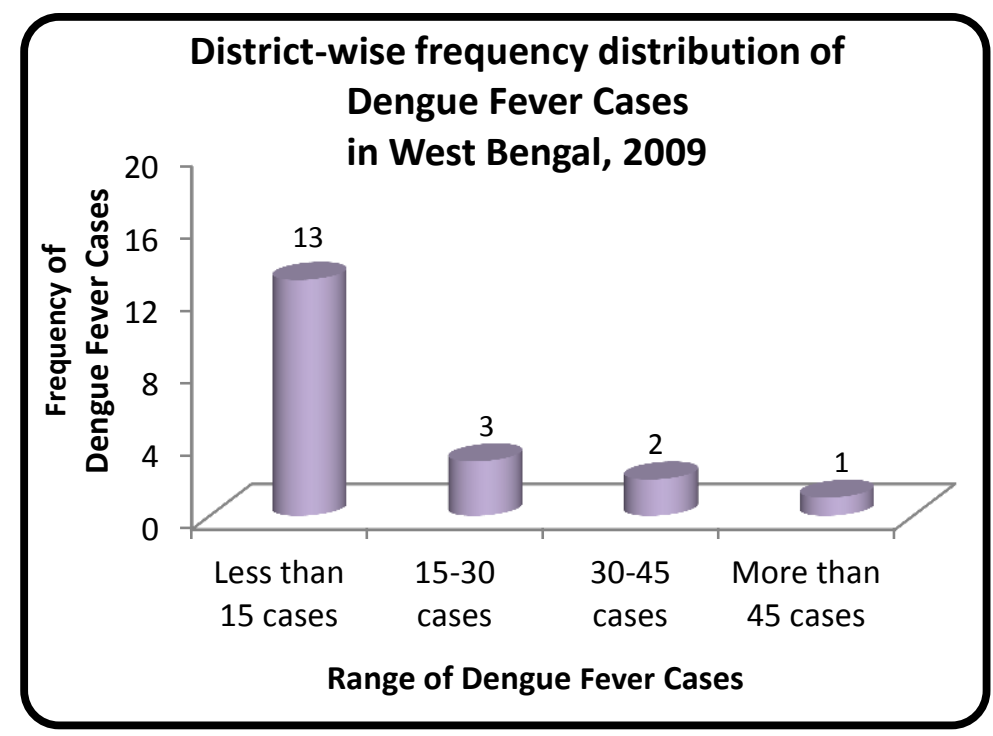

Fig.5

Data Source: Govt. of West Bengal

The study of year-wise number of incidences of dengue fever in three administrative divisions of West Bengal has revealed that during the period 2009-12 the number of incidences of the disease has been highest in the Presidency administrative division and least in the Jalpaiguri administrative division [Fig.6].

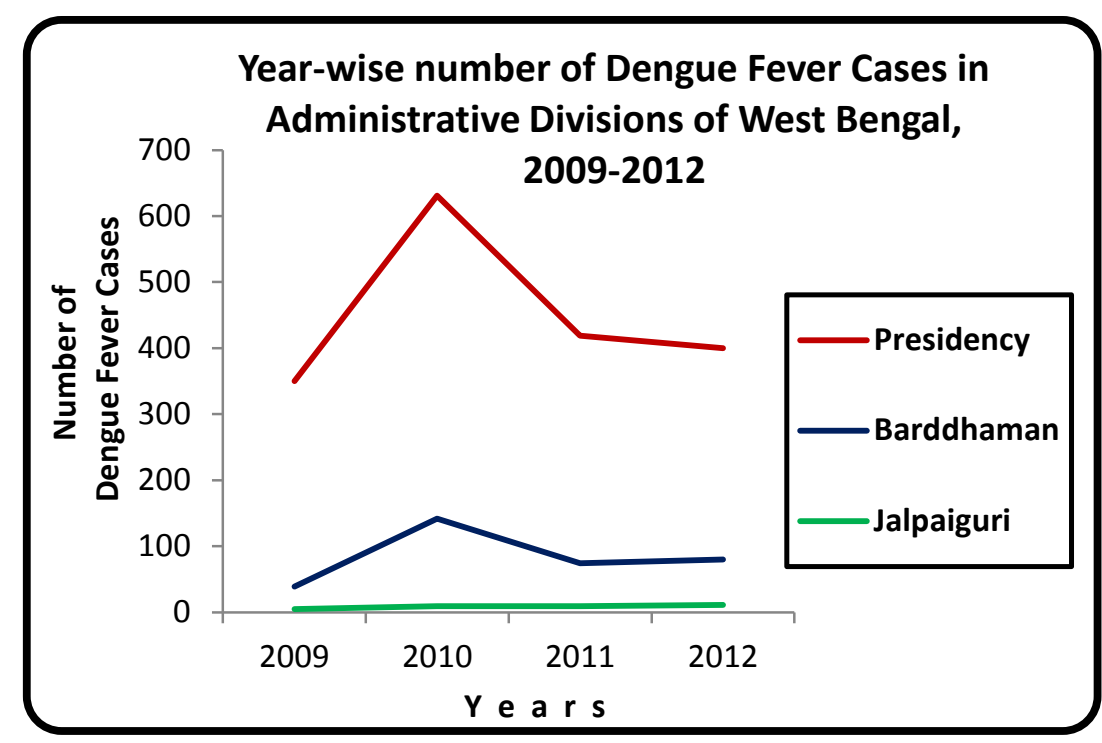

Fig.6

Data Source: Govt. of West Bengal

\section{Scenario of Dengue Fever in Kolkata}

Kolkata (erstwhile Calcutta) has a long recurrent history of outbreak of DF among districts of West Bengal. Serological surveys conducted in 1960 and re-survey in 1966 showed a high endemicity of dengue in Kolkata (Chatterjee, et.al. 1969). Though the first case of DF was documented in 1824, DHF was first reported in the city during 1963-65.In recent years the disease has affected the city dwellers during monsoon and postmonsoon season though in 2012 the trend of the disease has exhibited a declining trend [Fig.7]. The incidences of the disease reach its peak during September and October though stray cases of dengue are reported from various corners of the city all round the year. DHF is distinct from classical DF and is characterized by an acute febrile illness followed by haemorrhagic diathesis, dengue shock syndrome and haemo-concentration. If the trend of incidences of DHF reported from various parts of the city during 1983-84 is analyzed it is evident that during this time the disease involved mostly children and young adults. It was the massive outbreak during 1990 that claimed quite a number of lives especially of the children due to DHF/DSS. The child population from the Central, North-eastern and Southern parts of the city was found to be suffering from acute form of the disease in 
1990. It was during this time that children below one year especially the one-three years age group were exposed to DHF/DSS which was rare prior to 1990.

Table.4: Serological Studies on Dengue Fever in Kolkata, 2005-2007

\begin{tabular}{|l|r|r|r|}
\hline \multicolumn{1}{|c|}{ Year } & Total dengue cases & Primary dengue cases & Secondary dengue cases \\
\hline 2005 (Aug-Dec) & 224 & 77 & 147 \\
\hline 2006 (Jan-Dec) & 62 & 23 & 39 \\
\hline 2007 (Jan-Dec) & 16 & 01 & 15 \\
\hline Total & $\mathbf{3 0 2}$ & $\mathbf{1 0 1}$ & $\mathbf{2 0 1}$ \\
\hline
\end{tabular}

(After Hati, 2009)

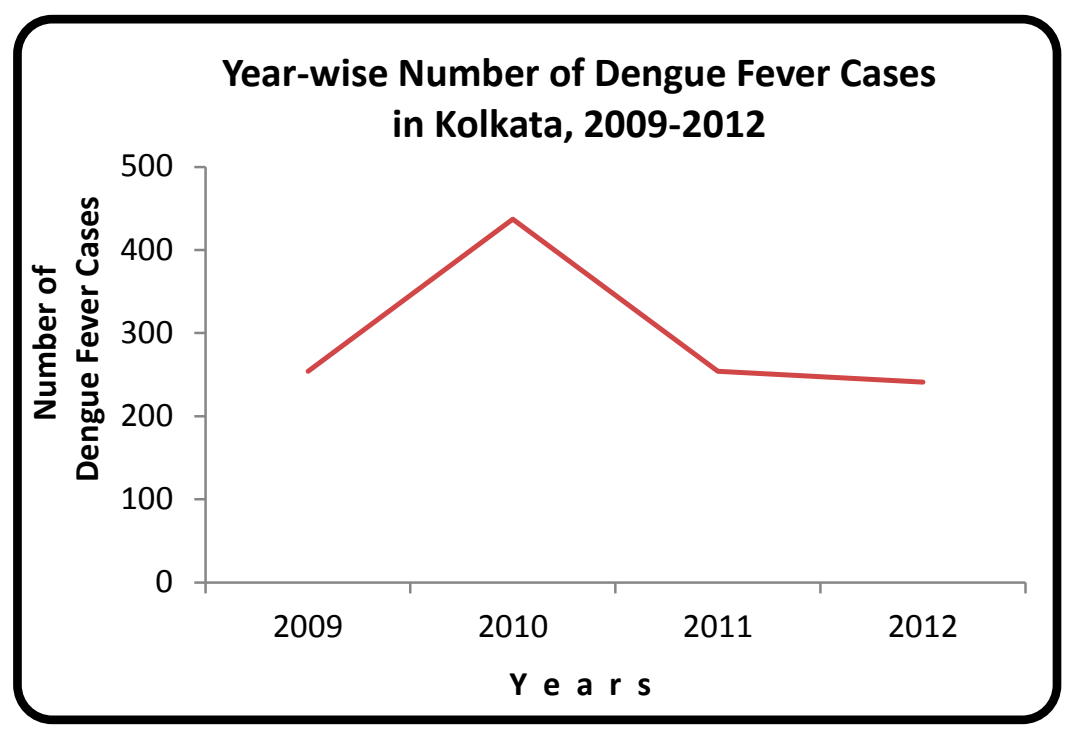

Fig.7

Data Source: Govt. of West Bengal

During 2005, 25.8 per cent of fever cases were found to be dengue while the figure was 9.24 per cent in 2007. The number of primary dengue cases was 77 in 2005, 23 in 2006 and 1 in 2007 while 147 total secondary dengue cases in 2005, 39 in 2006 and 15 in 2007 were reported from various parts of the city[Table.4]. The secondary dengue cases constituted approximately 66.5 per cent of all dengue cases. Studies have revealed that the primary dengue cases were highest in the months of September and October during 200507. The number of secondary dengue cases was also highest in September (69) in 2005, October (20) in 2006 and in December (5) in 2007 (Hati, 2009). The percentage share of Kolkata to total cases of dengue fever in the state was 63.66 per cent in 2009 which declined to 49.08 per cent in 2012[Fig.8]. 


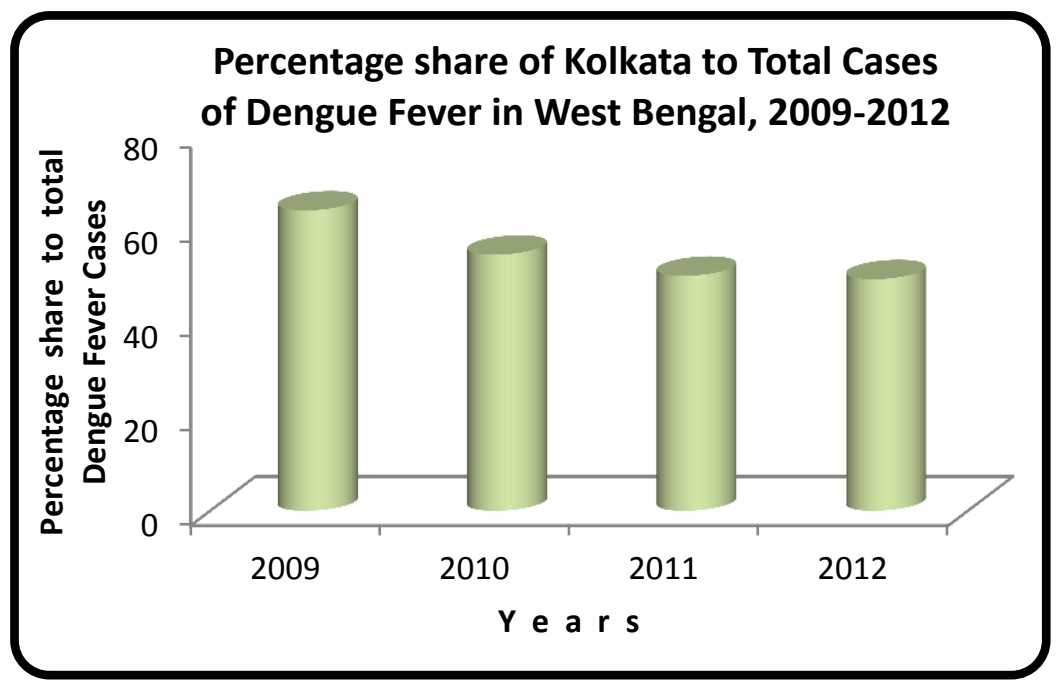

Fig.8

Data Source: Govt. of West Bengal

Among all other districts under Presidency division which includes Nadia, Murshidabad, North 24 Parganas, South 24 Parganas and Haora the city of Kolkata leads in the number of incidences of DF during 2009-12[Fig.9]. The number of patients during 2009 in Kolkata was 254 which experienced a tremendous rise of 437 in 2010 and a consecutive decline of 58 per cent (approx.) in 2011.

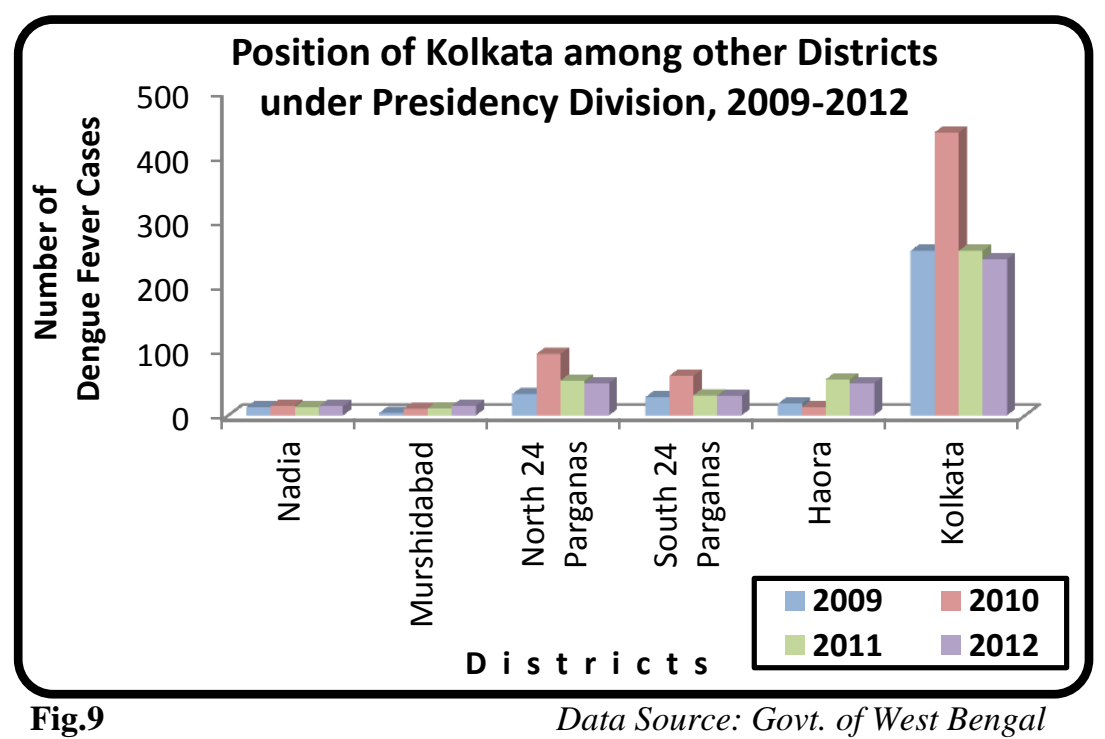

The survey conducted in the Government run health institutions have revealed that the maximum inflow of patients is received from neighbouring states of Bihar, Jharkhand and Assam while huge inflow of patients is experienced from surrounding districts of North 24 Parganas, South 24 Parganas, Haora, Purba Medinipur, Paschim Medinipur and from the city itself [Fig.10]. Here the percentage share of city dwellers is comparatively less in case of treatment conducted in the city Government hospitals due to the reason that the non-slum communities prefer private nursing homes where the pressure of patients are much less than the available infrastructure. The difference in cost of treatment in Government hospitals and private nursing homes is huge due to which the slum dwellers prefer the former than the latter. The population from the slum dwellings mainly visit the Government run hospitals than private nursing homes owing to their economic constraints in the city. 


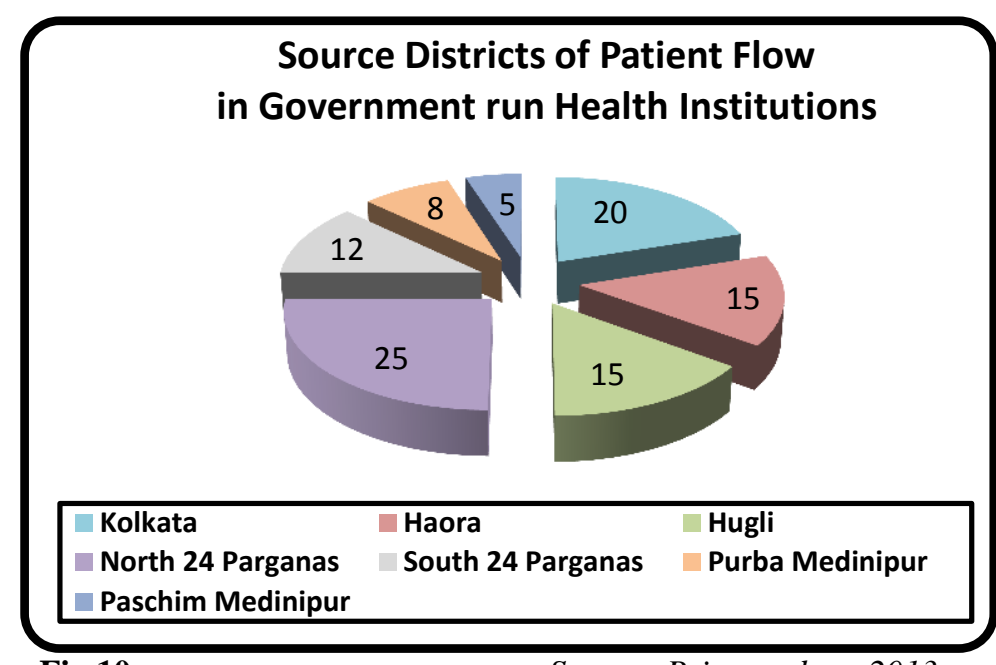

Fig.10 Source: Primary data, 2013

The incidences of outbreak of dengue fever have been quite high in case of slum dwellers than non-slum communities in the city [Fig.11]. The reasons have been the socio-economic and living conditions of the slum families. The inadequate urban amenities which include unhygienic environ of living, open drains, condition of water logging during monsoon season and seasonal spells of shower and lack of proper sanitary conditions. Their condition is even more worsened by their state of poverty, illiteracy, low level of awareness and failure of the Government health workers to reach these areas. Among the slum dwellers of the city the female population in the age groups of 0-15 years, 15-30 years and 30-45 years have been found to be more vulnerable than their male counterparts. The picture is quite reverse in case of 45-60 years age group as well as above 60 age group of population [Fig.12]. It is noteworthy to mention here that the below poverty line (BPL) group of population is more affected by the disease than the slum dwellers. The mortality rate is even high among the BPL group than the slum families.

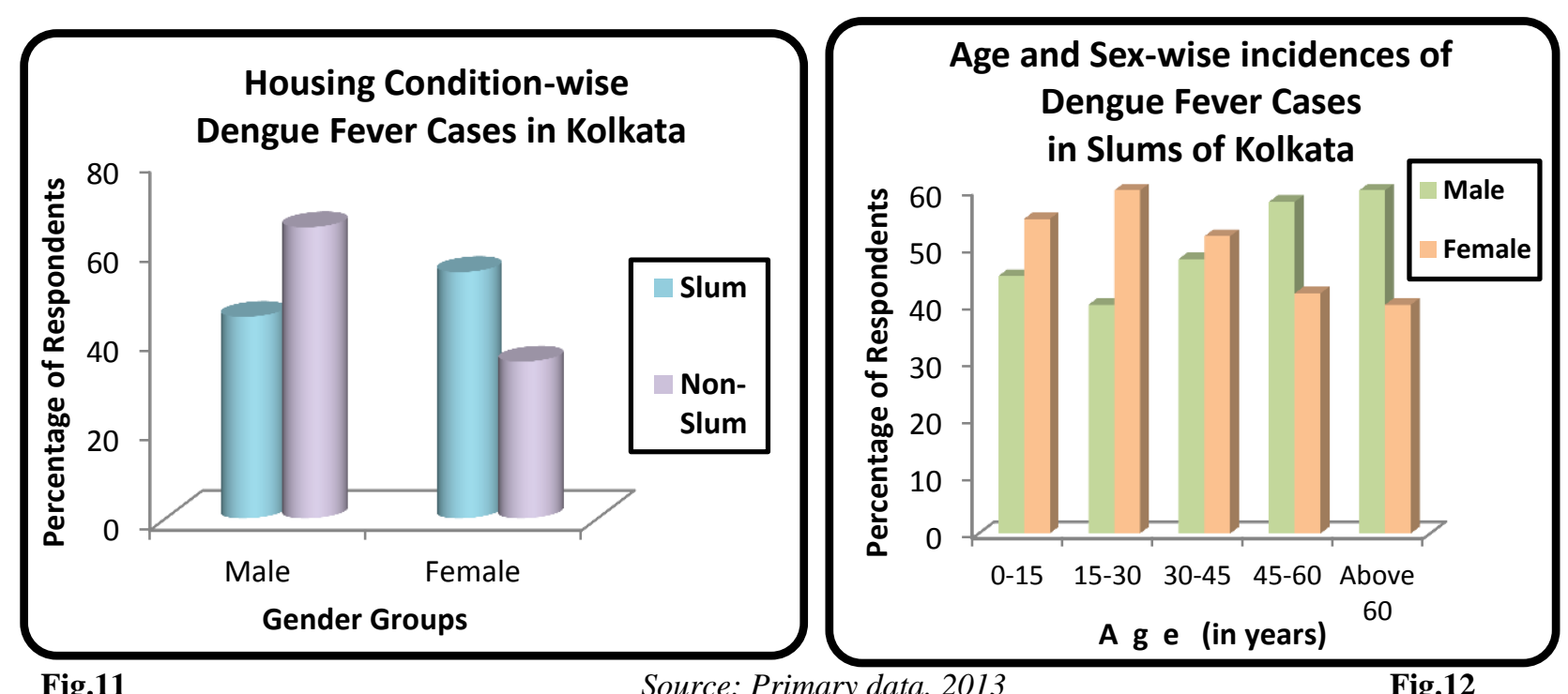

Fig.11

Source: Primary data, 2013

Fig.12

\section{Role of Government in Controlling the Outbreak of the Disease}

The city of Kolkata experiences recurrent outbreak of DF/DHF every year claiming a number of lives each year. To control the outbreak, spread and death incidences from the disease the State Government has taken a number of initiatives especially in the slum areas of the city. Local clinics and blood testing health camps are run in the Boroughs of the city besides the Ward health units for each of the municipal ward. Government health workers visit the slum households to create awareness among the people regarding the disease. Public hoardings and banners are put up at public places and along road-side. The Government arranges for free treatment and blood tests of suspected dengue patients for below poverty line group of population in 
Government run hospitals. Cleaning of environ especially in the slum areas by draining out storm water and spraying pesticides are other significant initiatives undertaken to arrest the outbreak and spread of the disease. In Government run hospitals some beds are reserved for dengue patients for their immediate treatment and to control death toll are amongst other initiatives undertaken by the State Government.

\section{Findings from the Study}

Dengue fever has emerged as one of the serious threats on human health in the state of West Bengal as well as in the city of Kolkata. Inter as well as intra-district disparities can be seen regarding the outbreak and controlling measures to combat the dreadful effects of dengue fever. The disease exhibits least number of incidences with almost no victims in the districts under Jalpaiguri division. The highest number of incidences claiming highest number of lives every year can be seen in the districts under Presidency division. The city of Kolkata suffers every year from severe outbreak of the disease especially during the monsoon and post-monsoon season though scattered cases of the disease are reported throughout the year. During the rainy season the streets become water logged thus facilitating the outbreak of the disease. Dengue has been identified as one of the fastest spreading infectious diseases in the city accompanied by chikungunya. The disease spreads from the saliva of the infected aedes mosquito which multiplies mostly in clear water. The slum as well as non-slum areas show heavy condition of water logging during monsoon season and the storm water is also retained in broken cans and containers along the road-side. Sometimes the initiatives of the local civic authorities become inadequate in controlling the outbreak of the disease. Since dengue fever is a highly infectious disease it spreads very fast especially in the slum areas which experience quite high death toll than non-slum areas. Lack of awareness coupled with illiteracy and poverty are the factors responsible for the high outbreak of the disease among slum dwellers. The people belonging from the BPL section are highly vulnerable to the disease. The lack of proper living condition along with adequate and nutritious diet decreases their resistivity to various diseases including dengue fever. A number of deaths occur due to wrong clinical findings and careless treatment of pathologists and physicians every year which further adds to the horrifying picture of the disease. The State Government has undertaken various measures to control the outbreak and spread of the disease which has actively worked in some areas where the outbreak could be controlled to some extent in recent years while in some areas of the city these initiatives have fall far short than the actual requirement.

\section{Conclusion}

Dengue fever continues to be a disease of concern both in West Bengal as well as in its capital city. The case burden of this vector borne disease continues to increase every year. Amongst the three administrative divisions, the Presidency division was found to be severely affected by the disease every year with Kolkata at its prime focus. The number of incidences and victims every year indicates that a more careful approach has to be undertaken to combat the disease. Community participation is required at root level both in urban and rural areas of the state. Awareness generation should be carefully planned especially for the slum dwellers and BPL group of population. The generation of higher level of awareness should be an orchestrated effort of both the Government and Non Government Organizations. The health care facilities provided at the Government run health units need improvement both in terms of infrastructure and availability of skilled health personnel. The draining out of storm water should be a rapid process to control the outbreak of the dengue fever in the urban slums. It would be ideal for the families to change water of the buckets everyday thus denying the scope of mosquito reproduction. The entomological survey should be carried out at regular interval to increase preparedness and combat the outbreak of dengue fever.

From Print Media

\section{References}

[1]. Chatterjee, S.N, Chakravarti, S.K, Chakraborty, M.S, Ray, S, Pal, S.R, Sarkar, J.K. [1969]. Re-survey of arbovirus antibody in the human sera after an interval of six years. Ind.Jour.Med.Res. Vol.57. New Delhi: Indian Council of Medical Research. Pp. 1629-1635

[2]. Government of India [2008]. Guidelines for Clinical Management of Dengue Fever, Dengue Haemorrhagic Fever and Dengue Shock Syndrome. New Delhi: Ministry of Health and Family Welfare. Pp.6-8

[3]. Halasa, Y.A, Dogra, V, Arora, N, Tyagi, B.K, Nandan, D, Shephard, D. [2011]. Overcoming data limitations: design of a multicomponent study for estimating the economic burden of dengue in India. Dengue Bulletein. Vol.35 (Dec). Geneva: WHO. Pp.1-4

[4]. Hati, A.K. [2006]. Studies on Dengue fever and dengue haemorrhagic fever in West Bengal State, India. Jour.Commun.Dis.Vol.38 [2]. Delhi:Indian Society for Malaria and communicable diseases. Pp. 124-129

[5]. Hati, A.K. [2009]. Dengue serosurveillance in Kolkata, facing an epidemic in West Bengal, India. Jour.Vect.borne.Dis. Vol. 46 (Sep). New Delhi: National Institute of Malaria Research. Pp. 197-201

[6]. Sharma, S.K, Ahluwalia, G. [2010]. Dengue Fever in India: An Overview. Medicine Update. Vol.20. Pp. 657-658

[7]. World Health Organization [2009]. Dengue-treatment, prevention and control. Geneva:WHO

From Electronic Media

www.wbhealth.gov.in accessed on: 17.11.2013

www.who.org accessed on: 27.11.2013

www.icmr.nic.in accessed on: 24.01.2014 